\title{
The potential for reducing TPP water consumption through the use of heat pumps
}

\author{
Milana Treshcheva ${ }^{1, *}$, Dmitry Treshchev $^{1}$, Irina Anikina ${ }^{1}$, and Sergei Skulkin ${ }^{1}$ \\ ${ }^{1}$ Peter the Great St. Petersburg Polytechnic University, St. Petersburg, Russian Federation
}

\begin{abstract}
Largest part of consumed water resources in Russian Federation is related to energy sector; accordingly, we need to develop measures to ensure their rational use. This paper analyzes the potential for reducing water consumption of thermal power plants by applying heat pumps in the condenser cooling system of a steam turbine plant. The calculations were performed for two CCGT-450 power units with three main options for technical water supply systems. The greatest environmental and economic effects are provided by the use of heat pumps at TPPs with a once-through water supply system. Utilization of all low-grade heat of the condenser cooling system of a steam turbine plant is irrational due to an increase in energy consumption for TPP own needs. With a further growth of tax rates for water intake from surface water bodies, positive effect of application of heat pumps in the condenser cooling system of a steam turbine plant will increase by an order of magnitude.
\end{abstract}

\section{Introduction}

The Russian Federation is one of the countries with rich water resources, that are conditionally inexhaustible natural resources of the Earth. However, under the influence of an anthropogenic factor, the chemical composition and physical state of the hydrosphere change; its biological value is being lost. In addition, fresh water, which accounts for only $2 \%$ of the total hydrosphere, is often spent not only on household needs of industrial enterprises, but also on production processes.

In accordance with the State report "On the State and Use of Water Resources of the Russian Federation in 2017" [1], the total water withdrawal from water bodies in the Russian Federation from 2000 to 2017, having a clear downward trend, still ranges from 69 to 86 billion $\mathrm{m}^{3}$. It should be noted that during this period, the percentage of water savings for production needs due to recycled and sequential water supply increased from 77 to $82.2 \%$, and transportation losses decreased from 8.5 to 6.9 billion $\mathrm{m}^{3}$.

At the same time, one of the characteristic problems of Russian economy is the lack of rationality in the use of water resources [2]. Thus, water consumption of the gross domestic product of Russian Federation significantly exceeds the similar indicators of the economies of Germany, France, the USA and Canada. High level of water capacity is characteristic to the economy of our country as a whole and as well as to certain industries and agriculture in particular.

The water strategy of the Russian Federation for the period until 2020 [3-12] means improving the rationality of the use of water resources. Main aim way to achieve this goal is to reduce water losses during transportation, to decrease specific water consumption in technological processes through the use of more efficient production technologies and to make consumption for household needs less [13-18]. The energy sector spends most of the water used in the country by industry (see Fig. 1) [1].

Accordingly, development, justification and implementation of measures aimed at ensuring the rational use of water resources in the energy sector, primarily by improving technological processes, is a relevant issue. This is of particular importance for areas with a tense water balance, where reduction of limited water resources in the production process allows maintaining sustainability of aquatic ecosystems.

\footnotetext{
* Corresponding author: milana.treshcheva@gmail.com
} 


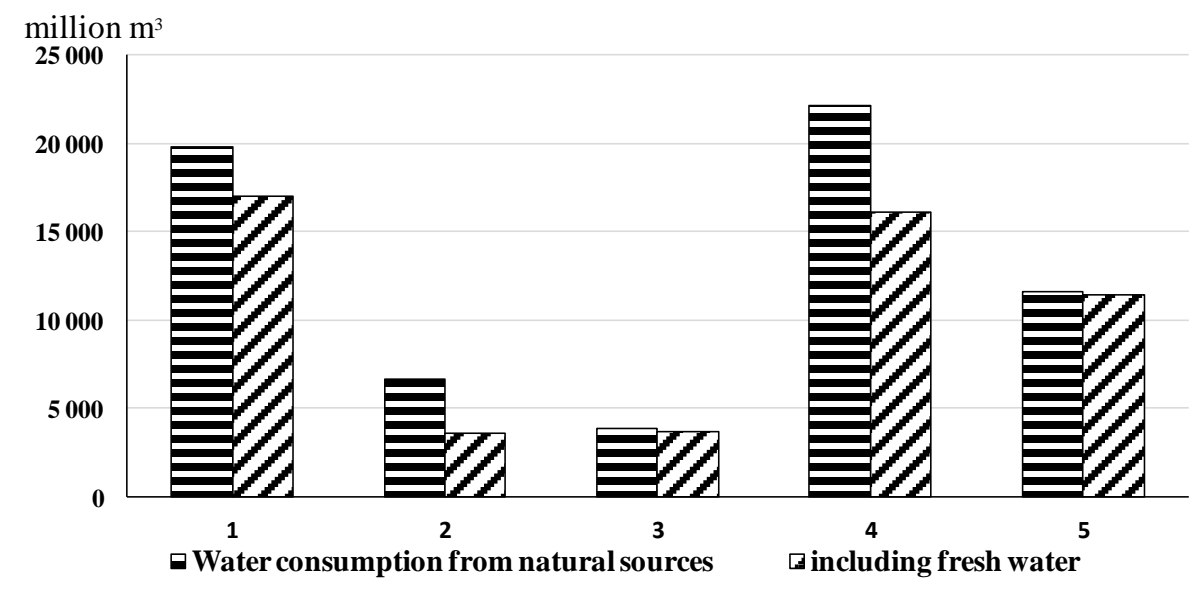

Fig. 1 Dynamics of water intake from natural sources by certain types of economic activity in the Russian Federation in 2017, mln $\mathrm{m}^{3}$ : 1 - Agriculture, forestry, hunting, fishing 2 - mining, 3 - manufacturing, 4 - electricity, gas and steam, air conditioning, 5 - water supply, sanitation, waste management, pollution control activities

The value of the TPP water consumption from a surface water body is primarily determined by the type of technical water supply system. In addition, the following factors influencce the consumption: time of year, production volumes, equipment composition, installed capacity, number of hours of operation of turbine units and auxiliary equipment, type of fuel, volumes of water losses used in technological processes, heating system and cycle feed systems, water treatment systems and hydraulic ash removal, the volume of water withdrawn for their own needs and for third-party organizations.

The water resources consumed by TPPs for organizing the process of generating electric and thermal energy are used in equipment cooling systems, as well as to compensate for steam and condensate losses in the cycle and for the needs of the chemical workshop for the preparation of additional water for the main cycle and make-up water. Even the most rational, from the point of view of water consumption, circulating systems with a cooling tower, water consumption for replenishment of the cooling system amounts to $90 \%$ of the total water consumption. Therefore, improvement of this technological process will make the most efficient reduction in the water consumption of TPP production possible.

Currently, one of the most promising, environmentally friendly, resource- and energy-saving technologies are heat pump technologies [19-20]. The use of heat pumps (HP) will allow not only to use the secondary fuel and energy resources (SER) generated at thermal power plants and to improve environmental performance (including lower specific water consumption), but also to increase economic efficiency by reducing water usage fees. Schematic solutions for the use of heat pump units (HPU) at thermal power plants have now been developed and studied [21-24].

One of the ways to incorporate HPU into the thermal circuit of a TPP is to introduce HP into the cooling system of a condenser of a steam turbine unit (STU) (see Fig. 2). The advantage of implementing such a circuit solution is determined not only by a significant amount of low-grade heat released in the cooling system of the STU condenser, but also by a sufficiently high temperature level, high consumption, absence of impurities, low chemical activity and insignificant fluctuations in the temperature and pressure of process water.

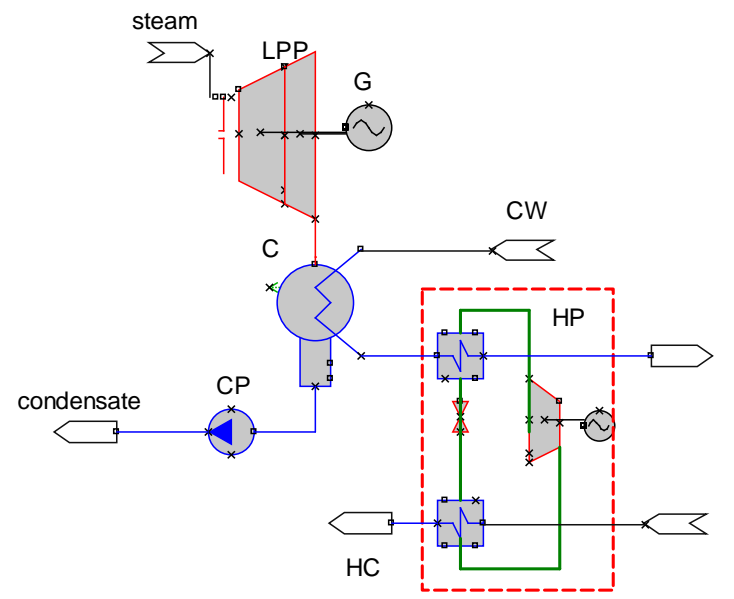

Fig. 2 The scheme of introduce HP into the cooling system of a condenser of a steam turbine unit:, LPP - low pressure part of turbine, G - electric generator, CW - cooling water, HP - heat pump, C - condenser, $\mathrm{CP}$ - condensate pump, $\mathrm{HC}$ - heat consumer

The use of circulating water supply systems, which in itself contributes to a decrease in the water consumption of thermal power plants by more than $97 \%$, still leaves the potential for its further minimization.

Another, quite promising way to rationalize water consumption is to use a reverse water supply system for thermal power plants with an air-condensation unit Geller. The Geller installation eliminates the evaporation or droplet entrainment of water from the condenser during its cooling, as in cooling ponds or in a cooling tower. This significantly reduces irretrievable water losses compared to direct-flow and reverse (with ponds coolers or cooling towers) water supply systems - up to $1 \%$ and $2 \%$ of gross water consumption, respectively. However, the operating experience of such a plant at 
TPP-14 (St. Petersburg) showed that the use of this technology is also accompanied by an increase in electricity consumption for own needs (by 0.5-1\%), a decrease in net output and an increase in specific fuel consumption, and, accordingly, increase of production costs. In addition, the use of the Geller installation, while complicating the thermal scheme of thermal power plants, does not increase the level of use of low-grade heat of the cooling system.

The purpose of this study is to analyze and evaluate the impact of HP on the water consumption of TPPs when using them in the plant's technological scheme.

North-West Thermal Power Plant branch of JSC Inter RAO Electric Power Plants was selected as the object of our study.

\section{Methods}

The potential for saving water resources due to the use of heat pump equipment in cooling systems at thermal power plants is determined by the capacity of HPP and the type of water supply system.

The calculation of the reduction in water consumption of TPPs due to the use of heat pumps was carried out in accordance with STO 70238424.27.100.080-2010 "Methodology for calculating the water consumption of TPPs from surface water sources taking into account the specifics of the operation of TPP equipment" [25].

In direct-flow water supply systems, the water consumption of TPPs from surface sources mainly depends on the total cooling water flow through the STU condenser and can be determined from the heat balance equation of the STU condenser. When utilizing a part of the low-grade heat of water cooling the condenser of a STU, in HP, this expression will have the following form:

$$
\mathrm{D}_{c} \times\left(i_{2}-i_{c}\right)=G_{c o o l}^{\prime} \times C_{w} \times\left(t_{2}-t_{1}\right)+Q_{l p h}
$$

where $D_{c}$ - steam consumption in the condenser, kgf;

$i_{2}$ - enthalpy of steam at the inlet to the condenser, $\mathrm{kJ} / \mathrm{kg}$;

$i_{c}$ - enthalpy of condensate, $\mathrm{kJ} / \mathrm{kg}$;

$G^{\prime}$ cool - reduced, due to the use of HP, the flow rate of cooling water from a surface source, kgf;

$$
C_{w} \text { - heat capacity of water, } \mathrm{kJ} /\left(\mathrm{kg}^{* \circ} \mathrm{C}\right) \text {; }
$$

$t_{2}$ - temperature of cooling water at the outlet of the condenser, ${ }^{\circ} \mathrm{C}$;

$t_{1}$ - temperature of cooling water at the inlet to the condenser, ${ }^{\circ} \mathrm{C}$;

$Q_{l p h}$ - low potential heat absorbed by the evaporator HP, MW.

Given the expression describing the relationship between the volume of low-grade heat perceived by the HP evaporator and the heat released from the HP condenser (2):

$$
\varphi=\frac{Q_{h p}}{Q_{h p}-Q_{l p h}}
$$

where $\varphi$ - HP conversion factor;

$Q_{h p}$ - heat release from HP, MW.

Reducing the flow rate of cooling water from a surface source due to the use of HP can be represented as follows (3):

$$
\Delta G_{t w}=\frac{1}{C_{w} \times\left(t_{2}-t_{1}\right)} \times\left(1-\frac{1}{\varphi}\right) \times Q_{h p}
$$

The relative decrease in the consumption of cooling water per 1 MW of power of the HP can be represented as follows (4):

$$
\Delta g_{t w}=\frac{1}{C_{w} \times\left(t_{2}-t_{1}\right)} \times\left(1-\frac{1}{\varphi}\right)
$$

In reverse water supply systems with a cooling tower, the water consumption of thermal power plants from surface sources is determined to a large extent by the magnitude of the losses of cooling water with evaporation and entrainment. Correspondingly, a decrease in the consumption of TPP process water as a result of the use of HP in circulating water supply systems with a cooling tower can be determined by formula (5).

$$
\Delta G_{t w}=\frac{Q_{h p}}{C_{w}} \times\left(1-\frac{1}{\varphi}\right) \times\left[k_{e v}+\frac{k_{e}}{\left(t_{2}-t_{1}\right)}\right]
$$

where $k_{e v}$ - coefficient taking into account the proportion of heat transfer by evaporation in the total heat transfer;

$k_{e}$ - coefficient taking into account the fraction of fluid entrainment for a given type of cooling tower.

The relative decrease in the consumption of cooling water per $1 \mathrm{MW}$ of power of the heat pump can be represented as follows (6):

$$
\Delta g_{t w}=\frac{1}{C_{w}} \times\left(1-\frac{1}{\varphi}\right) \times\left[k_{e v}+\frac{k_{e}}{\left(t_{2}-t_{1}\right)}\right]
$$

In circulating water supply systems with a storage pond, the water consumption of thermal power plants from surface sources is determined by the amount of cooling water losses with evaporation in the cooling structure (7).

$$
\Delta G_{t w}=\frac{Q_{h p}}{C_{w}} \times\left(1-\frac{1}{\varphi}\right) \times k_{e v}
$$

A relative decrease in the consumption of cooling water per $1 \mathrm{MW}$ of HP capacity can be represented as follows (8):

$$
\Delta g_{t w}=\frac{1}{C_{w}} \times\left(1-\frac{1}{\varphi}\right) \times k_{e v}
$$

We should bear in mind that competition in the production sector of the electric power industry forms special requirements for the efficiency of thermal power plants. Accordingly, the rationality of the implementation of any technology aimed at improving 
the technological process from an environmental point of view should be confirmed by the economic effect calculation [26-28].

In general terms, the economic effect of reducing the water consumption of TPPs due to the use of heat pumps can be presented as follows:

$$
E_{\text {wcon }}=T_{w c o n} \times \Delta G_{t w}
$$

where $E_{\text {wcon }}$ - the annual economic effect of reducing the water consumption of TPPs due to the use of heat pumps, rubles / year;

$T_{\text {wcon }}$ - tariff for water consumption, rub / $\mathrm{t}$;

$\Delta G_{t w}-$ reduction of TPP technical water consumption due to the use of THP, $\mathrm{t} /$ year. the condensers of the STU TPP for any technical water supply systems helps to reduce the volume of water consumption. Figure 3 shows the calculation of the maximum reduction in the water consumption of TPPs during utilization of the full amount of low-grade heat released in the cooling system of the condensers of the STU of two CCGT-450 power units, with different water consumption systems. So, with annual electricity production in the amount of 5973 million kWh and heat supply in the amount of 1216 thousand Gcal, the total water consumption will be: for a direct-flow system 192 million tons, for a circulating system with a cooling tower - 3.9 million tons, for a circulating system with a cooling pond - 2.5 million tons. The annual loss of low potential heat in the cooling system of the condensers of the STU will amount to 2593 thousand Gcal.

\section{Results and Discussion}

Calculation results analysis for the North-Western TPP showed that the use of HPP in the cooling schemes of

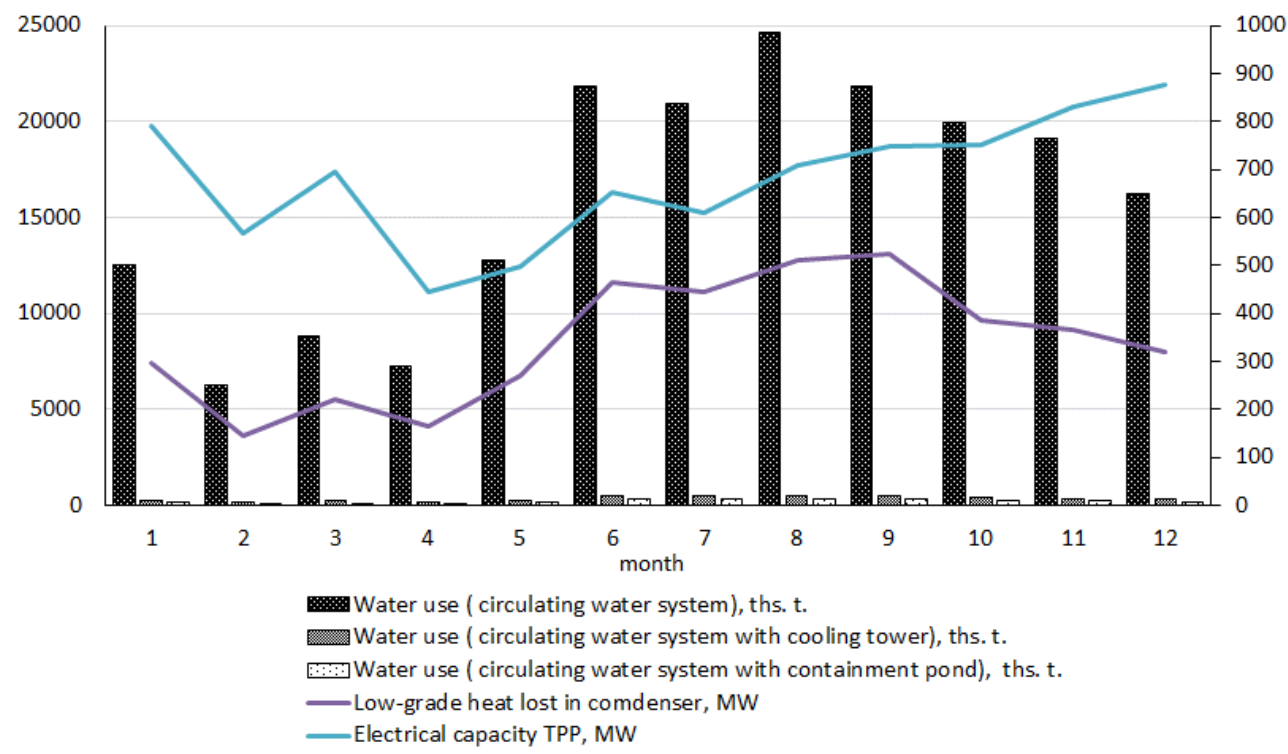

Fig. 3 Potential of reducing TPP water consumption when using HP

By far, the greatest economic and environmental effect is achieved by the use of HP in thermal circuits with a once-through water supply system. According to Decree of the Government of the Russian Federation No. 1509 "On Rates of Charges for the Use of Water Facilities", starting from 2015 and up to 2025, an annual indexation of tariffs is envisaged upwards [29]. This will undoubtedly lead to a significant increase in energy enterprises expenses, even if water consumption is maintained at the same level. Thus, under the conditions of a steady increase in tax rates for the use of water bodies, it becomes reasonable to implement measures to reduce costs for the use of water bodies, including circulating water supply systems.
Figure 4 shows the dynamics of changes in the payment for water use for TPPs with a reverse water supply system for the period from 2014 to 2025 (the calculation of the change in the cost of annual water consumption of TPPs was carried out in accordance with the Tax Code of the Russian Federation). In particular, if in 2014 the payment for water use in the amount of 3855 thousand tons (TPP with a reverse system of technical water supply with a cooling tower) amounted to 995 thousand rubles, in 2025 the payment for water use in the same volume will amount to 4624 thousand rub., increasing more than 4.5 times. 


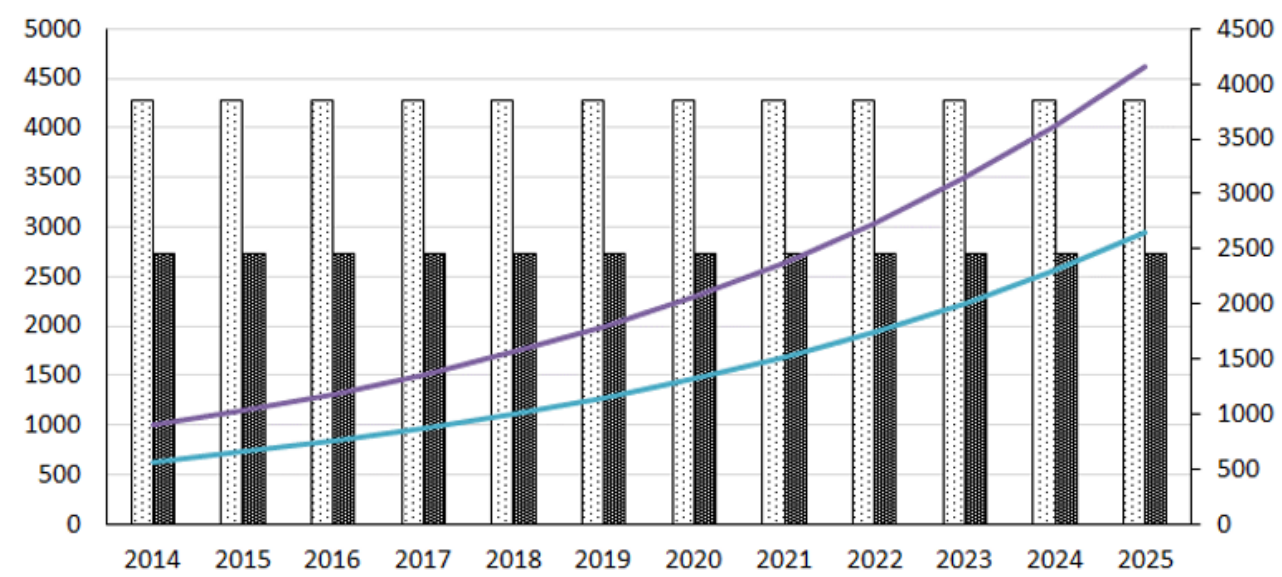

$\ldots$ Annual water use (circulating water system with cooling tower), ths. t.

mannal water use (circulating water system with containment pond), ths. $t$.

Fig. 4 Dynamics of the expected change in payment for water use at TPPs from 2014 to 2025

We should consider the fact that even though lowpotential heat is emitted in significant volumes in the cooling systems of thermal power plants, only a certain amount of it can be rationally used in heat pumps. For example, when utilizing the total amount of heat released in the cooling system of condensers of thermal power plants with two CCGT-450 units, taking into account the economically acceptable level of conversion coefficient of HPI $\varphi=3 \ldots 5$, energy consumption for own needs will increase from $2 \%$ to 10 ... $20 \%$, which will entail a significant decrease in productive supply and an increase in specific fuel consumption for the supply of electricity by $20 \ldots 50 \mathrm{gt} / \mathrm{kWh}$. It is not acceptable for a power plant operating in a competitive electricity market. At the same time, when using a heat pump with a capacity of $45 \mathrm{MW}$, the compressor capacity will be no more than $15 \mathrm{MW}$, which will lead to an increase in electricity consumption for own needs from $2 \%$ to $4 \%$, and specific fuel consumption for the supply of electricity by $4 \ldots 6 \mathrm{~g}$. $\mathrm{t} / \mathrm{kWh}$. At the same time, the amount of low-grade heat used in heat pumps, and, accordingly, the reduction in water consumption of thermal power plants due to the use of HPU, will be from 6 to 20\% of the possible. However, even such a slight decrease in water consumption in the future can bring a noticeably positive economic result.

Figure 5 shows the dynamics of changes in the annual perspective of the total and partially used in HPU the amount of low-grade heat for the circulating technical water supply system with a cooling tower. Provided that the energy consumption for own needs of the TPP equipment with HPU does not exceed $4 \%$, and the HPU conversion factor is 5 :

- average power spent on the HPU compressor drive will be $16 \mathrm{MW}$;

- average volume of utilized low-grade heat will be $64 \mathrm{MW}$ (with the maximum possible $343 \mathrm{MW}$ );

- average annual capacity of HPU will be $80 \mathrm{MW}$.

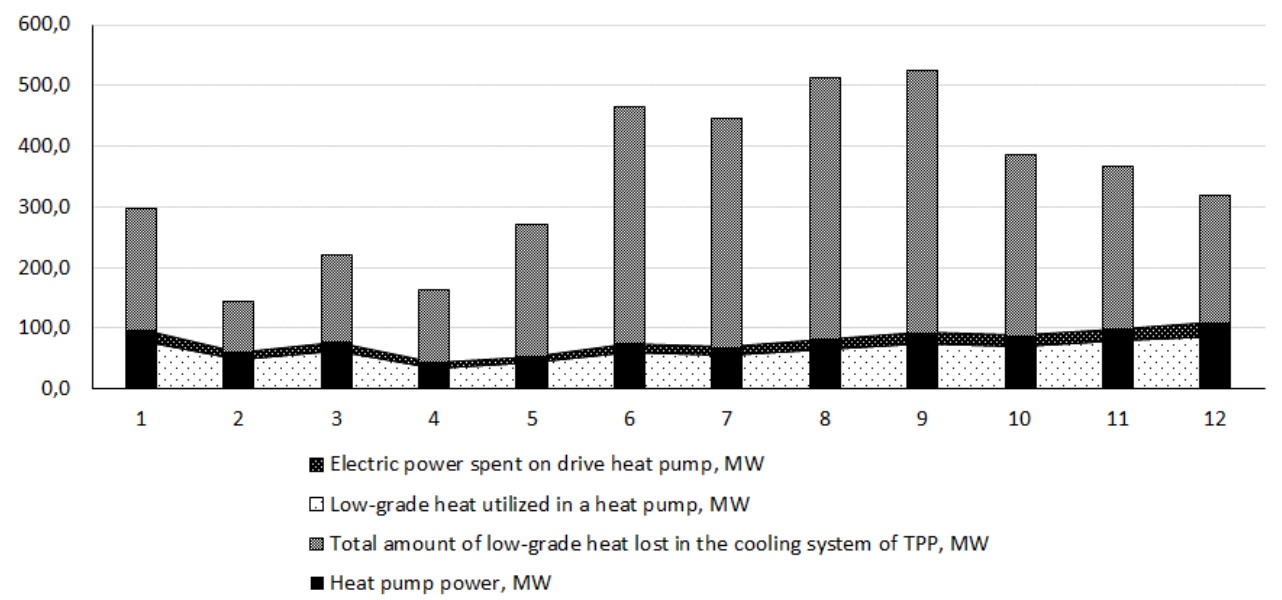

Fig. 5 Dynamics of changes in the total and partially used in the HP amount of low-grade heat 


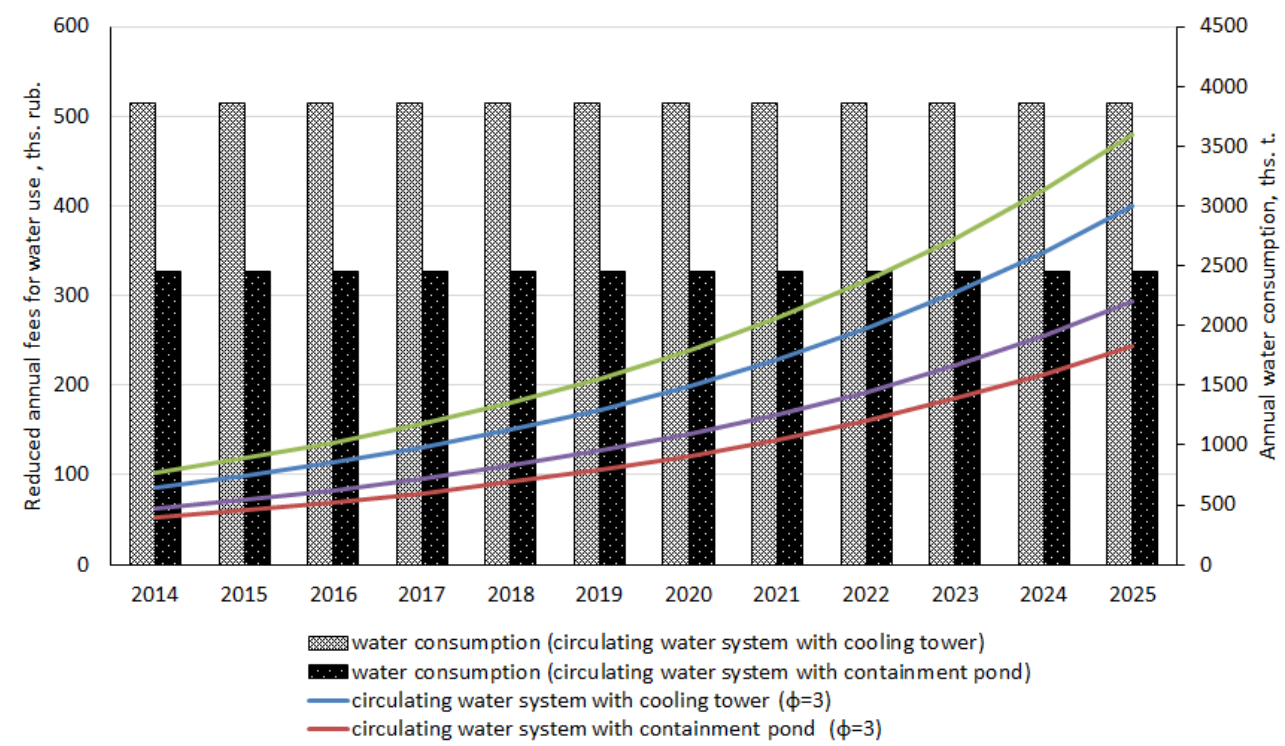

Fig. 6 Dynamics of changes in water use charges for circulating water supply systems

Figure 6 shows the dynamics of changes in water use charges for TPPs with a reverse water supply system for the period from 2014 to 2025 (calculation was carried out in accordance with the Tax Code of the Russian Federation). In 2014, a reduction in the annual payment for water use due to the use of HPP (with a capacity of 45 MW), when utilizing from 6 to $20 \%$ of the total amount of low-grade heat released in the cooling system of the condensers of the STU condensers, would be from 50 to 100 thousand rubles, then in 2025, a similar figure will be from 250 to 500 thousand rubles. The reduction in annual water consumption will be from 200 to 400 thousand tons, with a total annual consumption of 2500 to 4000 thousand tons.

If there is a continued trend towards an increase in fees for water use, with the same volumes of electricity and heat production, a decrease in annual costs for the consumption of water resources due to the use of HPU (45 MW) will make up from 500 to 970 thousand rubles in 2030, and in 2035 from 1,000 thousand rubles to 2,000 thousand rubles.

We should also take in to consideration that the operation of direct-flow water supply systems is accompanied by thermal pollution of water bodies. The use of HP will allow, if not eliminate, then to significantly reduce this type of negative environmental impact of TPPs. In addition, the inclusion of HP in the circulation circuit of process water cooling of TPP units opens up additional possibilities for regulating the temperature at the entrance to the turbine condensers. It becomes possible to reduce the fuel consumption of TPPs by reducing burnout or increasing fuel economy by vacuum in the condenser.

\section{Conclusions}

The use of heat pumps will reduce the negative impact on the environment of TPPs:

- with direct-flow water supply by reducing return water consumption in the amount of 192 million tons / year;
- with circulating water supply with a cooling tower due to the reduction of irretrievable water consumption in the amount of 3.9 million tons / year;

- with circulating water supply with a cooling pond by reducing irrevocable water consumption in the amount of 1 million tons / year.

Utilization of the full amount of low-grade heat released in the cooling system of the condensers of a STU can be irrational due to an increase in energy consumption for own needs from 2 to $19 \%$.

Currently, the use in heat pumps from 6 to $20 \%$ of the low-grade heat of the TPP cooling system will save the water costs:

- for direct-flow water supply - 8-10 million rubles / year;

- for reverse water supply with a cooling tower - 0.2 million / year

- for recycled water supply with a cooling pond 0.1 million rubles / year.

With the trend of increasing tax rates for water withdrawal from surface water bodies within the established limits for water use by 2025, it is expected that the potential savings in costs associated with the consumption of TPP water will increase by 2 times, by 2030 by 4.7 times and by 2035 by 9 times.

\section{References}

1. State report "The state and use of water resources of the Russian Federation in 2017", 217 (2018)

2. M. Boikova, D. Krupnikova, Globalization of Freshwater Resources: Innovative Management Strategy. Foresight-Russia 4 (2), 4-17 (2010)

3. D. Sklarew, J. Sklarew, Integrated Water-Energy Policy for Sustainable Development. Foresight and STI Governance 12(4), 10-19 (2018)

4. J.-F. Hake, L. Proskuryakova, New Energy Sources, Technologies, and Systems: The Priority of Social, Climate, and Environmental Issues, Foresight and STI Governance 12 (4), 6-9 (2018) 
5. J. Hojnik, M. Ruzzier, T. Manolova, Eco-Innovation and Firm Efficiency: Empirical Evidence from Slovenia, Foresight and STI Governance 11 (3), 103-111 (2017)

6. D. A. Gaynanov, O. G. Kantor, E. S. Kashirina, Synergetic Modelling of the Russian Federation's Energy System Parameters, Economy of Region 4, 357-369 (2015)

7. A. Grechukhina, O. V. Kudryavtseva, E. Yu. Yakovleva, Evaluation of the Development of the Renewable Energy Markets in Russia, Economy of Region 12 (4), 1167-1177 (2016)

8. I. G. Polyanskaya, V. V. Yurak, Balanced Natural Resource Management of a Region: Estimation by Dynamic Normal Technique, Economy of Region 14 (3), 851-869 (2018)

9. S. Filippov, New Technological Revolution and Energy Requirements, Foresight and STI Governance 12 (4), 20-33 (2018)

10. V. V. Dobrodey, Forecast Parameters Disintegration and Coordination of The Socio-Economic Development and Fuel and Energy Balance of a Region, Economy of Region 18 (2), 291-304 (2015)

11. T. O. Tagaeva, V. M. Gilmundinov, L. K. Kazantseva, Ecological Situation and Environmental Protection Policy in Russian Regions, Economy of Region 12 (1), 78-92 (2016)

12. A. Kovalev, L. Proskuryakova, Innovation in Russian District Heating: Opportunities, Barriers, Mechanisms, Foresight-Russia 8 (3), $42-57$ (2014)

13. K. Voloshin, Y. Bocharov, E. Gyulikhandanov, S. Sopozhnikov, E. Kolpishon, V. Barilovich, B. Matisov, G. Topazh, B. Lyamaev, V. Nagornyy, Applicability of energy storage units to electric transport, E3S Web of Conferences 9101006 (2019)

14. D.A. Cauich-López, L.F. Barrera Payan, A.M.N. Abdelhalim, E. Socolova, A. A. Sinitsyn, Irina G. Akhmetova, Small-Scale Steam Generation from Local Solid Waste, International Journal of Civil Engineering and Technology $10(2), 2118-2129$ (2019)

15. A. Sebelev, A. Kirillov, G. Porshnev, K. Lapshin, A. Laskin, International Scientific Conference on Energy, Environmental and Construction Engineering (EECE-2018) (2018)

16. J. Song, Y. Wang, S. Li, C. He, D. Wang, L. Zheng, F. Yang, Z. Wu, Z. Zhang, Numerical and experimental study of $\mathrm{La}-\mathrm{Ni}$ hydriding kinetics based on the varying-size model, Chemical Engineering Science 176, 580-599 (2018)

17. N.I. Vatin, I.I. Pestryakov, Sh.T. Sultanov, T. Ogidan, Y.A. Yarunicheva, A.P. Kiryushina, Water vapour by diffusion and mineral wool thermal insulation materials, Magazine of Civil Engineering 81 (5), 183-192 (2018)

18. E.S. Zalata, Y.Y. Shavrov, K.I. Strelets, M.S. Emelyanova, Productivity of microalgae as biofuel for bioadaptive systems of facades, Magazine of Civil Engineering 81 (5), 43-51 (2018)

19. I.D. Anikina, V.V. Sergeyev, Heat pumps' application for energy efficiency rising of steampower HPP, St. Petersburg St. Polytec. Un. Journal 3 (178), 56-61 (2013)

20. I.D. Anikina, V.V. Sergeyev, N.T. Amosov, M.G. Luchko, Heat pumps application in flow-sheet of heat generation at thermal power plants, Int. Sc. Journal for Altern. Energy and Ecology 3-4 (191192), 39-49 (2016)

21. M.A. Molodkina, Use of heat pump in of turbogenerator air cooling closed circuit system, St. Petersburg St. Polytec. Un. Journal 2 (123), 81-85 (2011)

22. M.A. Molodkina, Energy saving in the high power CHP due to the utilization of low-grade heat of cooling tower blowdown, St. Petersburg St. Polytec. Un. Journal 3 (130), 84-88 (2011)

23. V.M. Borovkov, A. Al Alavin, Heat pump with twostage condenser, Ind. Power Engineering 8, 40-43 (2007)

24. I.D. Anikina, V.V. Sergeyev, N.T. Amosov, M.G. Luchko, Use of heat pumps in turbogenerator hydrogen cooling systems at thermal power plant, Inter. Jour-l of Hydrogen Energy 42, 636-642 (2017)

25. STO 70238424.27.100.080-2010, Methods of calculating the water consumption of TPP from the surface water sources taking into account the specifics of the equipment (2010)

26. ISO 14031:2013, Environmental management Environmental performance evaluation - Guidelines (2013)

27. ISO 14045:2012, Environmental management Eco-efficiency assessment of product systems Principles, requirements and guidelines (2012)

28. ISO/TR 14062:2002, Environmental management Integrating environmental aspects into product design and development (2002)

29. Resolution of the Government of the Russian Federation №1509 from December 26 (2014) 